\title{
Analysis of Fouling Characteristics of Diatomite Ceramic Membrane Using Filtration Models
}

\author{
YANG Yanqing ${ }^{1,2}$, QIU Yan ${ }^{1,2, a}$, LIU Yanhui ${ }^{1,2}$, ZHAO Yan ${ }^{1,2}$, LIjing $^{1,2}$, ZHANG yubo $^{1,2}$ \\ ${ }^{1}$ School of Architectural Engineering, Yunnan Agricultural University, Kunming, 650201, Yunnan, China \\ ${ }^{2}$ Key Laboratory of Urban and Rural Water Safety and Water Saving and Emission Reduction in Colleges and Universities of Yunnan \\ Province, Kunming, 650201, Yunnan, China
}

\begin{abstract}
Ceramic membrane has made rapid progress in industrial/municipal wastewater treatment and drinking water treatment owing to its advantageous properties over conventional polymeric membrane. The ceramic membrane processes are a rapidly emerging technology for water treatment, yet virtually no information on the performance and fouling mechanisms diatomite ceramic membrane. In this study, filtration experiments were carried out using a mixture of humic acid and kaolin which simulated surface water under constant pressure to reveal fouling characteristics of the filtration of the diatomite ceramic membrane. The results showed that the removal rate of $\mathrm{VU}_{254}$ was $52 \% \sim 70 \%$, and turbidity was $90 \% \sim 95 \%$ when treat mixed water of $5-10 \mathrm{mg} / \mathrm{L}$ kaolin and humic acid. And membrane surface retention and membrane pore adsorption were the mainly removal routes. And the flux slowly decreases, rapidly decreases, gradually decreases and stabilizes were three processes of diatomite ceramic membrane fouling. And the first and third stages of membrane fouling mainly caused by complete blocking, and the second stage was mainly controlled by standard blocking. The study found that humic acid would cause both the pore blocking and the fouling of the membrane surface when turbidity was present, especially the membrane surface pollution, it was the major factor of diatomite ceramic membrane fouling.
\end{abstract}

\section{Introduction}

Membrane separation technology as an efficient and stable separation technology, have been widely used in water treatment field [1]. However, in the process of water treatment, because of pollutants adsorption in the membrane hole led to the pore diameter become smaller and deposition on the surface causes blocked formed membrane fouling. It would be reduced the service efficiency and service life [2].

Inorganic turbidimetric substances and natural organic compounds (NOM) are mainly found in natural water. The former is mainly composed of suspended particles, while the latter is mainly humic acid [3]. Many studies have shown that natural organic compounds are the main cause of film pollution [4-6].

In recent decades, ceramic membrane has made rapid progress in wastewater treatment and drinking water treatment owing to its advantageous properties compare with conventional polymeric membrane [7]. The beneficial characteristics of ceramic membranes include fouling resistance, high permeability, good recoverability, chemical stability, and long life. Therefore, ceramic membranes hold great promise for potential applications in water treatment [8]. Diatomite as a material with abundant reserves, low price, abundant pores, huge specific surface area and strong absorbability, scholars are studying the preparation and modification of diatomite ceramic membrane. However, most of the researches focuses on the fouling mechanism of polymeric membrane processes membrane, while virtually no information on the performance and fouling mechanisms diatomite ceramic membrane.

In this study, Fouling mechanisms of diatomite ceramic membrane in filtering process was studied. To analysis the membrane fouling mechanism, filtration experiments were carried out performed with ceramic diatomite ceramic membrane under the constant pressure to treat kaolin and humic acid mixed water. The membrane permeate flux in filtering process was detailed analysis using four classical Hermia's models to identify the mechanism of membrane fouling. And the main influencing factors also been analysed. It can provide technical support for the control of the pollution of the ceramic membrane.

\section{2 materials and methods}

\subsection{Equipment}

The diatomite ceramic membrane water purification designed equipment was shown in Figure 1. It was composed of feed tank, water pump, pressure gauge, controller, ceramic membrane, flow meter and clean water tank. The ceramic membrane module adopts the domestic tubular diatomite ceramic membrane, the effective area of the membrane is $0.034 \mathrm{~m} 2$, and the average aperture of the membrane is $0.1 \mu \mathrm{m}$.

\footnotetext{
a Corresponding author: qy0323@ynau.edu.cn
} 


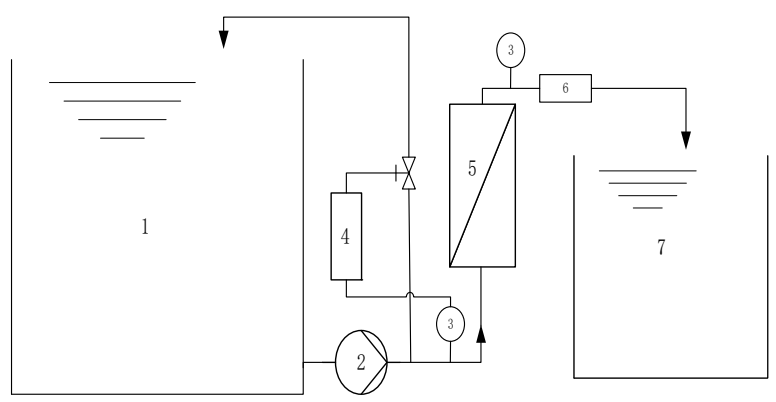

1.Feed tank 2. pump 3. Pressure gauge 4. PLC controller 5. Ceramic film 6. Flow meter 7. Clean water tank

Figure 1. Schematic diagram of membrane process.

\subsection{Filtration experiments and procedures}

Kaolin and humic acid were used to simulate inorganic particulate matter and organic matter in natural water respectively. The factor levels were $5 \mathrm{mg} / \mathrm{L}$ and $10 \mathrm{mg} / \mathrm{L}$ to respectively simulate raw water with different concentrations of inorganic particulate matter and natural organic matter. The experimental feed water quality was shown in table 1.

Table 1. Feed Water Quality for Experiment.

\begin{tabular}{|c|c|c|}
\hline Experimental & $\begin{array}{c}\text { humic acid } \\
/ \mathrm{mg} \cdot \mathrm{L}^{-1}\end{array}$ & $\begin{array}{c}\mathrm{kaolin} / \mathrm{mg} \cdot \mathrm{L}^{-} \\
1\end{array}$ \\
\hline $\mathrm{a}$ & 5 & 5 \\
\hline $\mathrm{b}$ & 5 & 10 \\
\hline $\mathrm{c}$ & 10 & 5 \\
\hline $\mathrm{d}$ & 10 & 10 \\
\hline
\end{tabular}

In this work, experiment adopts constant pressure filtration method. Every test used the same ceramic membrane. the membrane used sand paper to cleaning ceramic membrane. After cleaning the flux of filtered pure water was test to to ensure that the initial state of membrane basic same. The filtration pressure was kept at $0.05 \mathrm{MPa}$ for 30 minutes test. Filtering water turbidity measurement method using $\mathrm{HACH}$ 2100 turbidity meter measurement; UV254 was determined by UV-9000S UV-visible spectrophotometer.

\subsection{Theoretical models}

It is generally believed that the membrane surface pollution (the formation and compression of the filter cake layer), and adsorption and blocking in the membrane holes are the main causes of membrane pollution [9]. Hermia summarized the blocking model under the constant pressure filtering mode $[10,11]$. The blocking model have been widely used to analysis the mechanism of membrane pollution $[12,13]$, as shown in Equation (1).

$$
\frac{d^{2} \mathrm{t}}{d V^{2}}=\mathrm{k}_{\mathrm{n}}\left(\frac{d t}{d \mathrm{~V}}\right)^{n}
$$

Where, $\mathrm{kn}$ is the model parameter, whose unit depends on $\mathrm{n} ; \mathrm{n}$ is the model constant that determines the type of membrane fouling.
When $\mathrm{n}$ values are different, four different membrane fouling models can be obtained [14]:

When $n=2$, equation ( 1 ) is the complete blocking model. This model assumes that particles deposit into the pore resulting in pore complete blocking.

$$
\begin{gathered}
\ln \left(\frac{\mathrm{J}_{0}}{\mathrm{~J}_{\mathrm{t}}}\right)=\mathrm{A}_{0} \mathrm{t} \\
A_{0}=K_{0} \mathrm{~J}_{0}
\end{gathered}
$$

Where, Jt is flux at time $\mathrm{t}, \mathrm{m} 3 /(\mathrm{m} 2 \cdot \mathrm{s}), \mathrm{J} 0$ is the initial flux, $\mathrm{m} 3 /(\mathrm{m} 2 \bullet \mathrm{s})$; A0 is the model parameter of complete pore blocking, S-1, K0 refers to the complete film pore blocking coefficient, $\mathrm{m}-1$, caused by material passing through the film per unit volume.

When $n=1$, Equation ( 1 ) is the intermediate blocking model. The model assumes that each particle reaches the membrane surface and participates in partial blockage of the membrane pore, and a few blocking the membrane pore.

$$
\begin{aligned}
\frac{\mathrm{J}_{0}}{\mathrm{~J}_{\mathrm{t}}} & =1+A \mathrm{t} \\
A & =K_{\mathrm{a}} \mathrm{J}_{0}
\end{aligned}
$$

Where, $\mathrm{A}$ is the intermediate blocking model parameter, $\mathrm{s}-1, \mathrm{Ka}$ is the intermediate film pore blocking coefficient, $\mathrm{m}-1$, caused by material passing through the film per unit volume.

When $n=1.5$, Equation (1) is the membrane pore blocking model (also known as the standard blocking model). This model assumes that the membrane pore is the same cylindrical, and the pollutant particle size is smaller than the membrane pore. And each particle reaching the membrane surface settles on the internal pore wall, cause decreasing of the effective pore size.

$$
\begin{gathered}
\frac{\mathrm{J}_{0}}{\mathrm{~J}_{\mathrm{t}}}=(1+B \mathrm{t})^{2} \\
B=K_{\mathrm{b}} \mathrm{J}_{0}
\end{gathered}
$$

Where, $\mathrm{B}$ is the standard pore blocking model parameter, $(\mathrm{m} \cdot \mathrm{s})-1 / 2, \mathrm{~Kb}$ is the pore blocking coefficient, m-1.

When $n=0$, Equation ( 1 ) is the cake filtration model. The model assumes that the surface and interior of the membrane have been filled with particles, and when the particles reach the membrane surface, they actually reach the particles with blocked pore, forming cake layer.

$$
\begin{gathered}
\frac{\mathrm{J}_{0}}{\mathrm{~J}_{\mathrm{t}}}=(1+C \mathrm{t})^{1 / 2} \\
C=2\left(\mathrm{R}_{\mathrm{c}} / \mathrm{R}_{\mathrm{m}}\right) K_{\mathrm{c}} \mathrm{J}_{0}
\end{gathered}
$$

Where, $\mathrm{C}$ is the filter cake layer model parameter, $(\mathrm{m} \cdot \mathrm{s})-1 / 2$; Rc is filter cake resistance, $\mathrm{m}-1$; $\mathrm{Rm}$ is the membrane resistance, $\mathrm{m}-1 ; \mathrm{Kc}$ is the filter cake layer resistance coefficient $(\mathrm{m}-1)$ formed by filter material per unit volume. 


\section{Results and discussion}

\subsection{Removal efficiency}

The removal rate of UV254 and turbidity under different feed conditions was shown in table 2 . It can be seen that the removal rate of VU254 was $52 \%-70 \%$, and the removal rate of turbidity was $90 \%-95 \%$. In comparison a, $\mathrm{c}, \mathrm{b}$ and $\mathrm{d}$, when the concentration of humic acid increased from $5 \mathrm{mg} / \mathrm{L}$ to $10 \mathrm{mg} / \mathrm{L}$, the removal rate of UV254 also respectively increased by $13 \%$ and $5 \%$. It indicated that the pollutants in the membrane pores and the sediments on the membrane surface had certain effects on the retention of organic matters [15]. And compared with experiments a, b, c and d, when kaolin concentration increased from $5 \mathrm{mg} / \mathrm{L}$ to $10 \mathrm{mg} / \mathrm{L}$, the removal rate of UV254 increased by $13 \%$ and $5 \%$ respectively. The results showed that the increase of kaolin may improve the removal rate of UV254, especially under the condition of low humic acid. This might because of particles may mitigate the irreversible fouling caused by humic acid [16].

Table 2. The removal rate of $U_{254}$ and turbidity under different feed conditions

\begin{tabular}{|c|c|c|}
\hline Experimental & $\mathrm{VU}_{254} / \%$ & turbidity $/ \%$ \\
\hline $\mathrm{a}$ & 52 & 90 \\
\hline $\mathrm{b}$ & 65 & 95 \\
\hline $\mathrm{c}$ & 65 & 92 \\
\hline $\mathrm{d}$ & 70 & 94 \\
\hline
\end{tabular}

\subsection{Flux variation}

Figure 2 shown the flux decline trend under different feed conditions. In all cases, it can be divided into three stages: the first stage is the gradual decrease of flux at the initial stage of filtration, and the decrease of flux is about $10 \%$ in this stage. In the second stage, flux drops rapidly, about $60 \%$. In the third stage, flux drops slowly and tends to be stable. Under different influent conditions, the degree of decline at the every stage presents $b>a>d>c$, indicated that the influence degree of the four inlet water qualities on membrane pollution is $\mathrm{c}>\mathrm{d}>\mathrm{a}>\mathrm{b}$. By comparing a and $\mathrm{c}, \mathrm{b}$ and $\mathrm{d}$, it was found that under the same kaolin conditions, membrane fouling degree increased with the increase of humic acid concentration. By comparing influent $\mathrm{a}$ and $\mathrm{b}, \mathrm{c}$ and $\mathrm{d}$, it was found that the addition of kaolin at the same humic acid concentration reduced membrane fouling to a certain extent, especially under the condition of $5 \mathrm{mg} / \mathrm{L}$ humic acid, membrane flux decreased significantly. Therefore, in order to find the causes about this result, the mechanism of membrane fouling should be analysed.

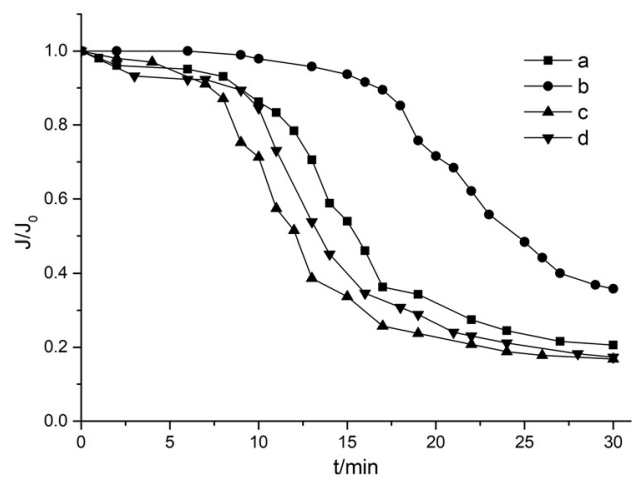

Figure 2. The change curve of specific flux under different feed conditions

\subsection{Analysis of membrane fouling mechanism}

The falling data of membrane flux under different feed conditions were fitted by Hermia model (Figure 3). above. It should be noted that the closer R2 value is to 1 , the more dominant mechanism of membrane fouling is. From figure 3, it showed that at different influent water closer of fitting were common. All the fitting degrees presented complete blocking model $>$ standard blocking model $>$ intermediate blocking model $>$ cake filtration model, indicating that diatomite mechanism of membrane fouling in the whole process was completely pore fouling, and the second was intermediate blocking model. In PVDF ultrafiltration membrane filtration was reached similar conclusions [17]. 

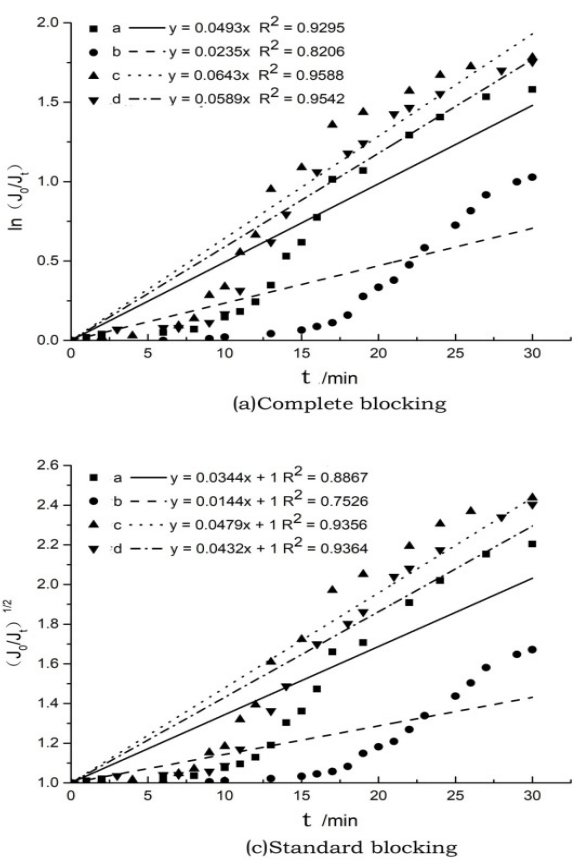

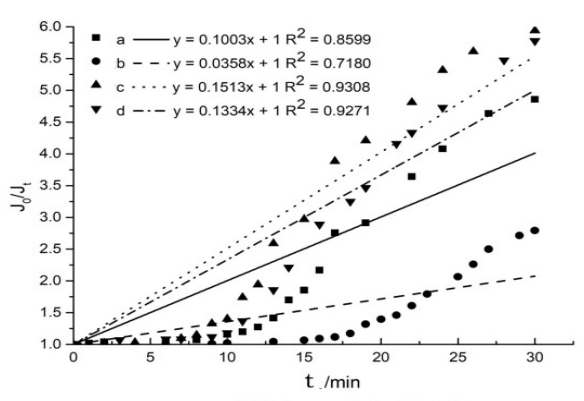

(b)Intermediate blocking

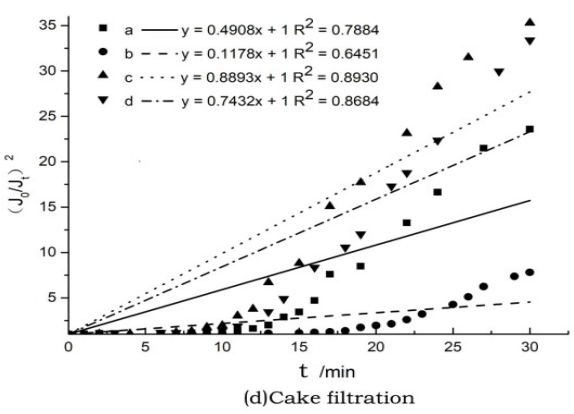

Figure 3. Fitting Hermia model under different feed conditions

Futhermore, the results were shown in table 3 through fitting the Hermia models at different stages. It can be seen from R2 that in the first stage, the correlation coefficient of the model with complete blocking above was better than that of other models, which means that complete blockage of membrane was the main cause of membrane fouling in the initial stage of filtering. In the second stage, the standard pore plugging models with different influxes showed a good correlation, with R2 all greater than 0.95 and all greater than the correlation coefficient of other models, indicating that the main reason affecting the rapid flux decline was the narrowing of membrane pores. In the third stage, correlation coefficients R2 of the four models with different influent water were all greater than 0.95 , showing a good fitting degree, indicating that all four pollution mechanisms existed in the later stage of filtration.

Table 3. Model coefficients and correlation coefficients $\left(\mathrm{R}^{2}\right)$ of Hermia model fitting at different stages

\begin{tabular}{|c|c|c|c|c|c|c|c|c|c|}
\hline \multirow{2}{*}{$\begin{array}{c}\text { experimen } \\
\mathrm{t}\end{array}$} & \multirow{2}{*}{$\begin{array}{c}\text { Fitting } \\
\mathrm{ime} / \mathrm{mi} \\
\mathrm{n}\end{array}$} & \multicolumn{2}{|c|}{$\begin{array}{c}\text { complete blocking } \\
\text { model }\end{array}$} & \multicolumn{2}{c|}{$\begin{array}{c}\text { intermediate blocking } \\
\text { model }\end{array}$} & \multicolumn{2}{c|}{$\begin{array}{c}\text { standard blocking } \\
\text { model }\end{array}$} & \multicolumn{2}{c|}{$\begin{array}{c}\text { cake filtration } \\
\text { model }\end{array}$} \\
\cline { 3 - 11 } & $\mathrm{A} 0$ & $\mathrm{R} 2$ & $\mathrm{~A}$ & $\mathrm{R} 2$ & $\mathrm{~B}$ & $\mathrm{R} 2$ & $\mathrm{C}$ & $\mathrm{R} 2$ \\
\hline$a$ & $0 \sim 8$ & 0.0092 & 0.9363 & 0.0095 & 0.8875 & 0.0047 & 0.8854 & 0.0197 & 0.8916 \\
\hline $\mathrm{a}$ & $0 \sim 21$ & 0.0417 & 0.8809 & 0.0645 & 0.9357 & 0.0257 & 0.9529 & 0.2181 & 0.8882 \\
\hline$a$ & $22 \sim 30$ & 0.0560 & 0.9979 & 0.1287 & 0.9570 & 0.0415 & 0.9508 & 0.6979 & 0.9678 \\
\hline$b$ & $0 \sim 17$ & 0.0044 & 0.8518 & 0.0097 & 0.7790 & 0.0023 & 0.7919 & 0.0097 & 0.7790 \\
\hline $\mathrm{b}$ & $18 \sim 26$ & 0.0224 & 0.9105 & 0.0881 & 0.9587 & 0.0130 & 0.9907 & 0.0881 & 0.9587 \\
\hline$b$ & $27 \sim 30$ & 0.0342 & 1.0000 & 0.2148 & 0.9969 & 0.0221 & 0.9946 & 0.2148 & 0.9969 \\
\hline $\mathrm{c}$ & $0 \sim 8$ & 0.0144 & 0.9518 & 0.0324 & 0.8971 & 0.0074 & 0.9103 & 0.0324 & 0.8971 \\
\hline $\mathrm{c}$ & $9 \sim 18$ & 0.0636 & 0.9363 & 0.4458 & 0.9347 & 0.0414 & 0.9814 & 0.4458 & 0.9347 \\
\hline$c$ & $19 \sim 30$ & 0.0668 & 0.9931 & 1.0944 & 0.9644 & 0.0521 & 0.9389 & 1.0944 & 0.9644 \\
\hline$d$ & $0 \sim 9$ & 0.0133 & 0.9401 & 0.0283 & 0.8884 & 0.0068 & 0.8162 & 0.0283 & 0.8884 \\
\hline $\mathrm{d}$ & $10 \sim 20$ & 0.0571 & 0.9227 & 0.3922 & 0.9816 & 0.0384 & 0.9911 & 0.3922 & 0.9816 \\
\hline$d$ & $21 \sim 30$ & 0.0619 & 0.9974 & 0.9508 & 0.9994 & 0.0480 & 0.9968 & 0.9508 & 0.9994 \\
\hline
\end{tabular}

The further analysis about the changes of the model parameters of three different stages from table 3 was carried out. The growth rate of model parameters at second and third stage was shown in figure 4 . The growth of standard blocking model parameter under the different feed water almost remained stable, indicating that the the existence of membrane pore and the stability of the pollutants adsorption. Meanwhile in the second and third stages of membrane fouling, the growth rate of cake filtration model was equal to the middle hole wall model for experiment $\mathrm{b}, \mathrm{c}$, d. As the assumption about the cake filtration model that standard and intermediate blocking woud finish, illustrate the intermediate blocking was growing rapidly, which indicates that the membrane surface existed serious fouling behavior [18]. When humic acid increased from $5 \mathrm{mg} / \mathrm{L}$ to 10 
$\mathrm{mg} / \mathrm{L}$, the intermediate blocking coefficient increased significantly at the second stage, and under the condition of $5 \mathrm{mg} / \mathrm{L}$ humic acid \& $10 \mathrm{mg} / \mathrm{L}$ kaolin slows down the cake filtration, but under the $10 \mathrm{mg} / \mathrm{L}$ humic acid, the cake filtration parameters did not improve, illustrating that the kaolin of humic acid adsorption was limited, humic acid on membrane table face wall dominated [9].

To further analysis main influence factors of difference fouling mechanisms, the second stage of the

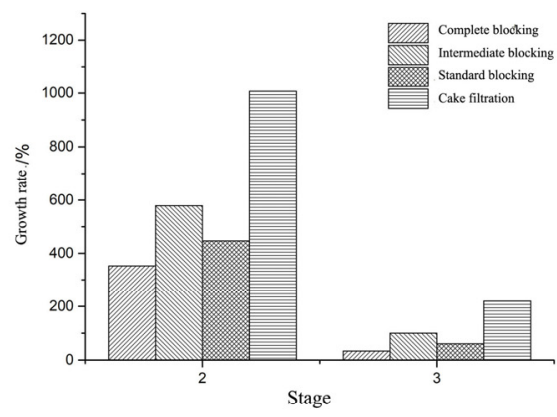

(a) $5 \mathrm{mg} \cdot \mathrm{L}^{-1}$ Humic acid $+5 \mathrm{mg} \cdot \mathrm{L}^{-1} \mathrm{Kaolin}$

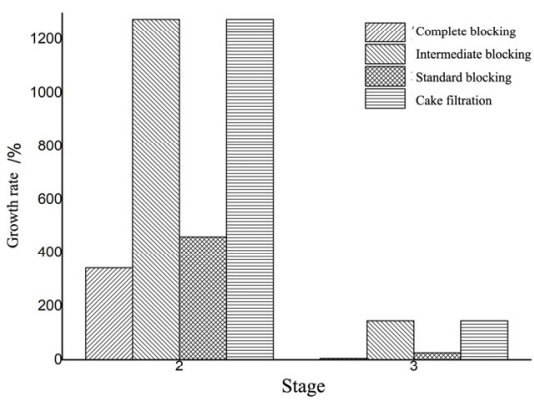

(c) $10 \mathrm{mg} \cdot \mathrm{L}^{-1}$ Humic acid $+5 \mathrm{mg} \cdot \mathrm{L}^{-1}$ Kaolin different model parameters of orthogonal analysis was conducted. The results was shown in table 4. The conclusion was that humic acid $p$ values were less than the $p$ values of kaolin, illustrating that the influence of humic acid on each stage of membrane fouling was greater than the kaolin. And intermediate blocking model and filter cake layer model of $p$ less than 0.1 , indicated that the humic acid had a great effect on the intermediate blocking and cake filtration fouling.

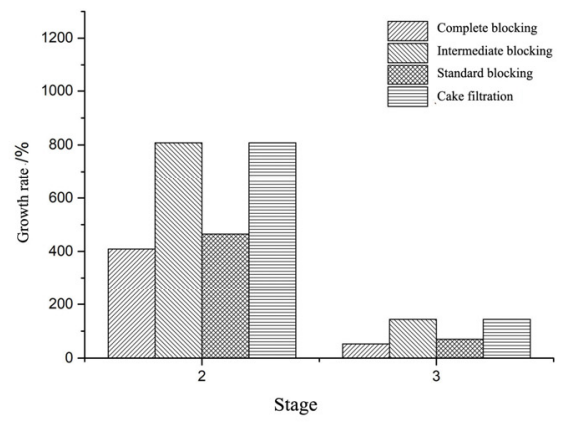

(b) $5 \mathrm{mg} \cdot \mathrm{L}^{-1}$ Humic acid $+10 \mathrm{mg} \cdot \mathrm{L}^{-1}$ Kaolin

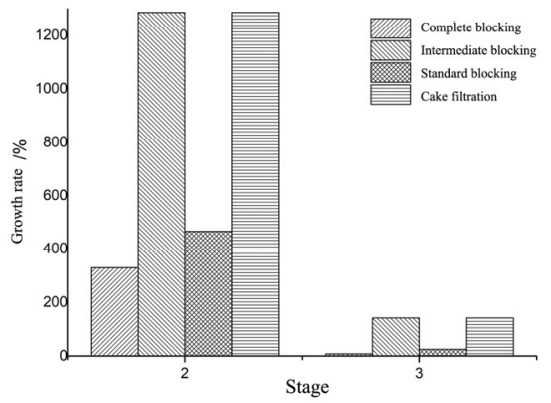

(d) $10 \mathrm{mg} \cdot \mathrm{L}^{-1}$ Humic acid $+10 \mathrm{mg} \cdot \mathrm{L}^{-1}$ Kaolin

Figure 4. The growth rate of the model coefficients under different stages

Summary of the above analyzs, the diatomite ceramic membrane fouling mechanism was that some kaolin particles which Particle diameter greater than or equal to membrane pore might blocked membrane pore when reach membrane surface and humic acid molecules were trapped in the crevices, causing the membrane pores to be completely blocked in the beginning[6]. As the filtering progresses, low molecular humic acid follow into the membrane pore and be adsorpted, membrane forming irreversible fouling [19]. At the same time, kaolin particles on the membrane surface, forming aggregation particle layer, humic acid adsorption on kaolinite, lead to the stability of humic acid and kaolinite colloid fouling [20], formed intermediate blocking and cake filtration fouling. Finally the membrane was completely blocked with humic acid concentration.

Table 4. The p-values of variance analysis about the Hermia model coefficients

\begin{tabular}{|c|c|c|c|c|}
\hline factor & $\begin{array}{c}\text { complete } \\
\text { blocking } \\
\text { model }\end{array}$ & $\begin{array}{c}\text { intermediate } \\
\text { blocking } \\
\text { model }\end{array}$ & $\begin{array}{c}\text { standard } \\
\text { blocking } \\
\text { model }\end{array}$ & $\begin{array}{c}\text { cake } \\
\text { filtration } \\
\text { model }\end{array}$ \\
\hline $\begin{array}{c}\text { humic } \\
\text { acid }\end{array}$ & 0.142 & 0.071 & 0.148 & 0.091 \\
\hline kaolin & 0.293 & 0.764 & 0.352 & 0.251 \\
\hline
\end{tabular}

\section{Conclusions}

1) The removal rate of VU254 was $52 \% \sim 70 \%$, and turbidity was $90 \% \sim 95 \%$, when using diatomite ceramic membrane to treat mixed water of $5-10 \mathrm{mg} / \mathrm{L}$ kaolin and humic acid. The membrane flux declines faster with the increase of humic acid concentration. Increasing the kaolin concentration can slow down the decline of membrane flux, especially under low humic acid conditions. The mainly removal of humic acid was achieved through membrane surface retention and membrane pore adsorption.

2) The diatomite ceramic membrane fouling could be divided into three stages: flux slowly decreases, rapidly decreases, gradually decreases and stabilizes. And the first and third stages of membrane fouling mainly caused complete blocking, and the second stage was mainly controlled by standard blocking.

3) Humic acid was the major factor of diatomite ceramic membrane fouling. And when turbidity was present, humic acid would cause both the pore blocking and the fouling of the membrane surface, especially the membrane surface pollution. 


\section{Acknowledgment}

This research was financially supported by the Yunnan Provincial Department of Education Fund (2019J0121), and Yunnan Basic Research Program Youth Project (2019FD097).

\section{References}

1. Y.-R. Chang, Y.-J. Lee and D.-J. Lee, Journal of the Taiwan Institute of Chemical Engineers, Membrane fouling during water or wastewater treatments: Current research updated, 94, 88-96, (2019)

2. W. Guo, H. H. Ngo and J. Li, Bioresour Technol, A mini-review on membrane fouling, 122, 27-34, (2012)

3. W. Yuan and A. L. Zydney, Environmental ence \& Technology, Humic Acid Fouling during Ultrafiltration, 34, 1-12, (2000)

4. P. Xiao, W. Zhang, F. Xiao, Z. Bi and D. Wang, Water ence \& technology, A novel approach using a fouling index to evaluate NOM fouling behavior in a low pressure ultrafiltration process, 14, 196-204, (2014)

5. M. A. Zazouli, S. Nasseri and M. Ulbricht, Desalination, Fouling effects of humic and alginic acids in nanofiltration and influence of solution composition, 250, 688-692, (2010)

6. I. Sutzkover-Gutman, D. Hasson and R. Semiat, Desalination, Humic substances fouling in ultrafiltration processes, 261, 218-231, (2010)

7. M. Chen, J. Zheng, R. Dai, Z. Wu and Z. Wang, Chemical Engineering Journal, Preferential removal of 2,4-dichlorophenoxyacetic acid from contaminated waters using an electrocatalytic ceramic membrane filtration system: Mechanisms and implications, 387, 124132, (2020)

8. H. Yang, S. Xu, D. E. Chitwood and Y. Wang, Frontiers of Environmental Science \& Engineering, Ceramic water filter for point-of-use water treatment in developing countries: Principles, challenges and opportunities, 14, (2020)

9. K. Gao, T. Li, J. Liu, B. Dong and H. Chu, Environmental Science: Water Research \& Technology, Ultrafiltration membrane fouling performance by mixtures with micromolecular and macromolecular organics, 5, 277-286, (2019)

10. J. Hermia, Transactions of the Institution of Chemical Engineers, Constant pressure blocking filtration laws-application to power-lawnonnewtonian fluids, 60, 187-193, (1982)

11. A. Rushton, Mathematical Models and Design Methods in Solid-Liquid Separation, (1985)

12. J. Peng, H. X. Zhu, L. W. Guo, L. I. Bo, X. J. Mao and G. M. University, Chinese Traditional \& Herbal Drugs, Fouling mechanisms of ultrafiltration membranes fouled with traditional Chinese medicine pectin based on Hermia model, (2019)

13. S. Heidari, M. Amirinejad and H. Jahangirian, Chemical Engineering \& Technology, Investigation of Fouling Mechanisms Using Surface Morphology and Physicochemical Membrane Features, (2019)

14. J. Jacob, P. Prádanos, J. I. Calvo, A. Hernández and G. E. Jonsson, Colloids and Surfaces A: Physicochemical and Engineering Aspects, Fouling kinetics and associated dynamics of structural modifications, 138, 173-183, (1998)

15. W. Jin and W. Xiao-Chang, Journal of Environmental ences, Ultrafiltration with in-line coagulation for the removal of natural humic acid and membrane fouling mechanism, 18, 880-884, (2006)

16. Y. H. Li, J. Wang, W. Zhang, X. J. Zhang and C. Chen, Chinese Science Bulletin, Effects of coagulation on submerged ultrafiltration membrane fouling caused by particles and natural organic matter (NOM), (2011)

17. Y. Teow, B. Ooi and A. Ahmad, Journal of Water Process Engineering, Fouling behaviours of PVDF$\mathrm{TiO} 2$ mixed-matrix membrane applied to humic acid treatment, 15, 89-98, (2017)

18. F. Xiao, P. Xiao, W. J. Zhang and D. S. Wang, Journal of Membrane ence, Identification of key factors affecting the organic fouling on low-pressure ultrafiltration membranes, 447, 144-152, (2013)

19. D. Jermann, W. Pronk, S. Meylan and M. Boller, Water Res, Interplay of different NOM fouling mechanisms during ultrafiltration for drinking water production, 41, 1713-22, (2007)

20. D. Jermann, W. Pronk, R. K?Gi, M. Halbeisenand M. Boller, Water Research, Influence of interactions between NOM and particles on UF fouling mechanisms, 42, 3870-3878, (2008) 